\title{
Mechanical and Tribological Behavior of Particulate Reinforced Aluminum Metal Matrix Composites - a review
}

\author{
G. B. Veeresh Kumar ${ }^{1 *}$, C. S. P. Rao ${ }^{2}$, N. Selvaraj ${ }^{2}$ \\ ${ }^{1}$ Research Scholar, National Institute of Technology, Warangal, (A.P), India \& Department \\ of Mechanical Engineering, S B M Jain College of Engineering, Jakkasandra (P), \\ Kanakapura (T), Ramanagara (D)-562 112, Karnataka, India. \\ ${ }^{2}$ Department of Mechanical Engineering, National Institute of Technology, Warangal, (A.P), \\ India. \\ *Corresponding author: veeru232@yahoo.com
}

\begin{abstract}
Aluminum Metal Matrix Composites (MMCs) sought over other conventional materials in the field of aerospace, automotive and marine applications owing to their excellent improved properties. These materials are of much interest to the researchers from few decades. These composites initially replaced Cast Iron and Bronze alloys but owing to their poor wear and seizure resistance, they were subjected to many experiments and the wear behavior of these composites were explored to a maximum extent and were reported by number of research scholars for the past 25 years. In this paper an attempt has been made to consolidate some of the aspects of mechanical and wear behavior of Al-MMCs and the prediction of the Mechanical and Tribological properties of Aluminum MMCs.
\end{abstract}

Key Words: Al-MMCs, Density, Hardness, Mechanical Properties, Wear, Prediction.

\section{INTRODUCTION}

Metal Matrix Composites are being increasingly used in aerospace and automobile industries owing to their enhanced properties such as elastic modulus, hardness, tensile strength at room and elevated temperatures, wear resistance combined with significant weight savings over unreinforced alloys [1-4]. The commonly used metallic matrices include $\mathrm{Al}, \mathrm{Mg}, \mathrm{Ti}, \mathrm{Cu}$ and their alloys. These alloys are preferred matrix materials for the production of MMCs. The reinforcements being used are fibers, whiskers and particulates [5]. The advantages of 
particulate-reinforced composites over others are their formability with cost advantage [6]. Further, they are inherent with heat and wear resistant properties [7, 8]. For MMCs $\mathrm{SiC}_{2} \mathrm{Al}_{2} \mathrm{O}_{3}$ and $\mathrm{Gr}$ are widely used particulate reinforcements. The ceramic particulate reinforced composites exhibit improved abrasion resistance [9]. They find applications as cylinder blocks, pistons, piston insert rings, brake disks and calipers [10]. The strength of these composites is proportional to the percentage volume and fineness of the reinforced particles [11]. These ceramic particulate reinforced Al-alloy composites led to a new generation tailorable engineering materials with improved specific properties $[12,13]$. The structure and the properties of these composites are controlled by the type and size of the reinforcement and also the nature of bonding [14-16]. From the contributions of several researchers, some of the techniques for the development of these composites are stir casting [17], powder metallurgy [18], spray atomization and co-deposition [19], plasma spraying [20] and squeeze-casting [21]. The above processes are most important of which, liquid metallurgy technique has been explored much in these days. Therefore the present paper summarizes the studies conducted by several investigators under sections mechanical and tribological behavior.

\section{PROPERTIES OF COMPOSITE MATERIALS}

From the nature and morphology of the composites, their behavior and properties can be predicted and the factors such as intrinsic properties, structural arrangement and the interaction between the constituents are of much importance. The intrinsic properties of constituents determine the general order of properties that the composite will display. The interaction of constituents results in a new set of properties. The shape and size of the individual constituents, their structural arrangement and distribution and the relative amount of each contribute to the overall performance of the composite. The factors that determine properties of composites are volume fraction, microstructure, homogeneity and isotropy of the system and these are strongly influenced by proportions and properties of the matrix and the reinforcement. The properties such as the Young's modulus, shear modulus, Poisson's ratio, coefficient of friction and coefficient of thermal expansion are predicted in terms of the properties and concentration and the most commonly used approach is based on the assumption that each phase component is subjected to either iso-stress or iso-strain condition.

\subsection{Physical Properties}

Density is the physical property that reflects the characteristics of composites. In a composite, the proportions of the matrix and reinforcement are expressed either as the weight fraction $(w)$, which is relevant to fabrication, or the volume fraction $(v)$, which is commonly used in property calculations. By relating weight and volume fractions via density $(\rho)$, the following expression is obtained ( $\mathrm{m}$ stands for matrix and $r$ for reinforcement material):

$$
\rho_{c}=\rho_{r} v_{r}+\rho_{m} v_{m}
$$


The above expression can be generalized and its general form is known as law of mixture and is as follows;

$$
X_{c}=X_{m} v_{m}+X_{p} v_{p}
$$

Experimentally, the density of a composite is obtained by displacement techniques [22] using a physical balance with density measuring kit as per ASTM: D 792-66 test method. Further, the density can also be calculated from porosity and apparent density values (sample mass and dimensions) [11].

The results of the several investigations [23-32] regarding the density of the $\mathrm{Al}_{2} \mathrm{O}_{3} / \mathrm{SiC}$ particle reinforced Al6061 and other aluminum alloys can be summarized as follows: the reinforcements $\mathrm{Al}_{2} \mathrm{O}_{3}$ and $\mathrm{SiC}$ enhance the density of the base alloy when they are added to the base alloy to form the composite. Moreover, the theoretical density values match with the measured density values of these composites. Further, Miyajima et.al. [5] reported that the density of A12024-SiC particle composites is greater than that of Al2024-SiC whisker reinforced composites for the same amount of volume fraction. From the above the increase in density can be reasoned to the fact that the ceramic particles possess higher density.

Further, the increased volume fraction of these particles contribute in increasing the density of the composites, also they have stated that the theoretical and measured density values of these composites match to each other. Additionally, the above discussions can be reasoned to the fact that the ceramic particles possess higher density.

To support the above findings, few composites were developed to study the density. The Al6061$\mathrm{SiC}$ and $\mathrm{Al} 7075-\mathrm{Al}_{2} \mathrm{O}_{3}$ particulate reinforced composites were developed by liquid metallurgy technique (stir casting route). The cast alloy and composite specimens were subjected to density test by two methods, i.e. weight to volume ratio and another being the rule of mixture, the obtained results are shown in the Figures 1 and 2.

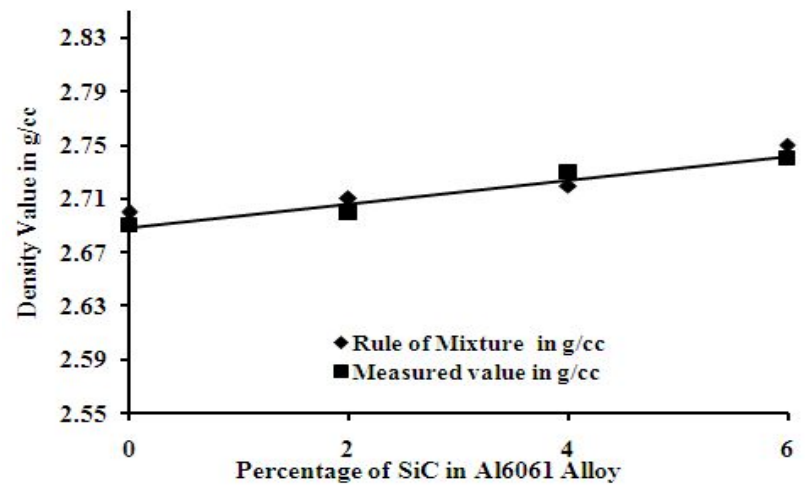

Figure 1. Theoretical and Experimental Density of A16061-SiC Composites.

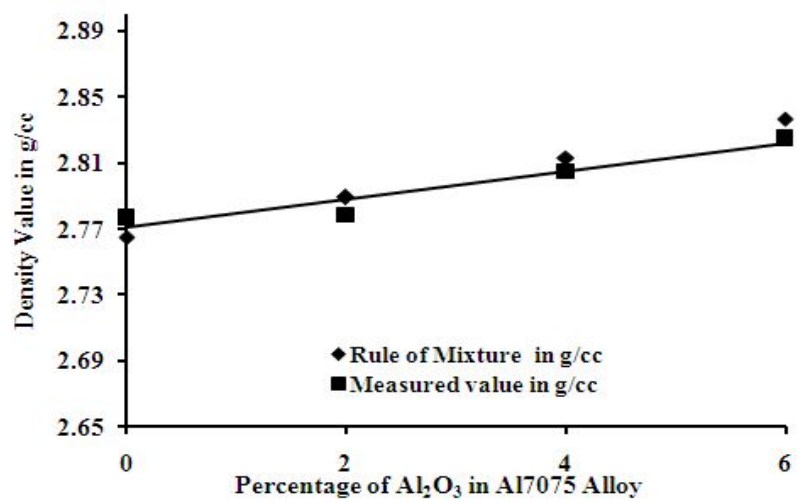

Figure 2. Theoretical and Experimental Density of $\mathrm{A} 17075-\mathrm{Al}_{2} \mathrm{O}_{3}$ Composites. 
From the above figures, it can be observed that the density of the composite is higher than the base matrix. Also, the density of the composites increased with increase in filler content. Further, the theoretical and experimental density values are in line with each other. The increase in density of composites can be attributed to higher density of reinforcement particles.

\subsection{Mechanical Properties}

\subsubsection{Hardness}

The resistance to indentation or scratch is termed as hardness. Among various instruments for measurement of hardness, Brinell's, Rockwell's and Vicker's hardness testers are significant. Theoretically, the rule of mixture of the type $H_{c}=v_{r} H_{r}+H_{m} v_{m}$ (suffixes 'c', ' $\mathrm{r}$ ', and 'm' stand for composite, reinforcement and matrix respectively and $v$ and $\mathrm{H}$ stand for volume fraction and hardness respectively) for composites [33] helps in approximating the hardness values. Among the variants of reinforcements, the low aspect ratio particle reinforcements are of much significant in imparting the hardness of the material in which they are dispersed (the hardness of fiber reinforced $\mathrm{MMC}<$ whisker reinforced $\mathrm{MMC}<$ particle dispersed MMC) [5]. The contributions of several researchers regarding the effect of reinforcement on hardness of the composites are summarized as follows;

The particulate reinforcements such as $\mathrm{SiC}, \mathrm{Al}_{2} \mathrm{O}_{3}$ and aluminide [34-36] are generally preferred to impart higher hardness. The coating of reinforcements with $\mathrm{Ni}$ [37] and $\mathrm{Cu}$ [16], also leads to good quality interface characteristics and hence contribute in improving hardness. TiC when dispersed in Al matrix, increases the hardness to weight ratio. Moreover, it imparts thermodynamic stability to the composites [38-40]. Abdulhaqq et.al. [41, 42], Hutchings [43] and Lloyd et.al. [44] explored the significance of hard ceramic particles in increasing the bulk hardness of Al-MMCs. Howell et.al. [45] and Vencl et.al.[46], reasoned the improvement of the hardness of the composites to the increased particle volume fraction. Wu [47] and Deuis [48] attributed this increase in hardness to the decreased particle size and increased specific surface of the reinforcement for a given volume fraction. Sug Won Kima et.al. [21] reasoned the increase in hardness of the composites to the increased strain energy at the periphery of particles dispersed in the matrix. Deuis et.al. concluded that the increase in the hardness of the composites containing hard ceramic particles not only depends on the size of reinforcement but also on the structure of the composite and good interface bonding [48]. The micro-hardness is a direct, simple and easy method of measuring the interface bonding strength between the matrix and reinforcement [49]. Particle reinforced composites possess better plastic forming capability than that of whisker or fiber reinforced composites [6]. Moreover, these composites exhibit excellent heat and wear resistances due to the superior hardness and heat resistance characteristics of the particles that are dispersed in the matrix [50-52]. Subramanian [53] incorporated Silicon in Alalloys and concluded that the higher wt.\% of Si improves the hardness of the composites and 
increased particle size improves the load carrying capability of the composites [54]. The heattreated alloy and composite exhibits better hardness [55-57], however, the over-aged condition may tend to reduce the hardness significantly [58].

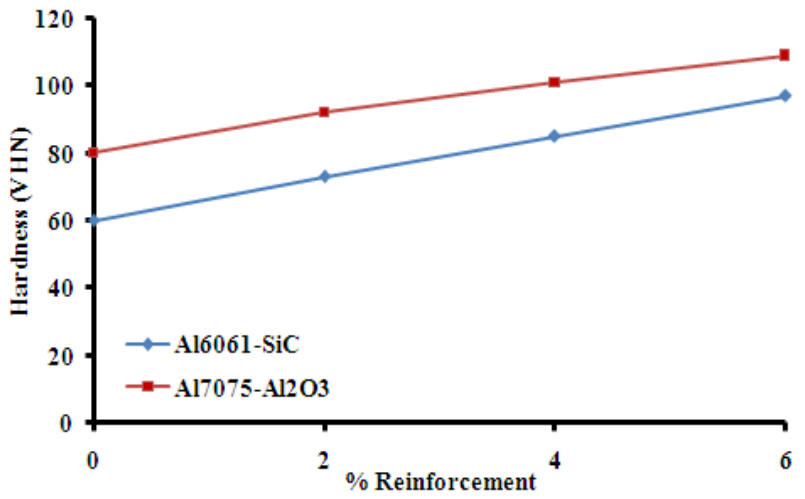

Figure 3. Variation of Vicker's Hardness of Al6061-SiC and $\mathrm{Al} 7075-\mathrm{Al}_{2} \mathrm{O}_{3}$ Composites.

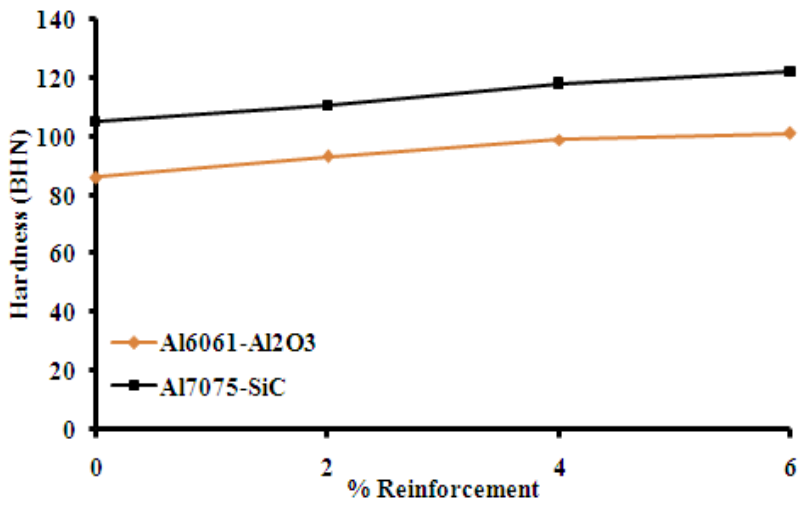

Figure 4. Variation of Brinell's Hardness of $\mathrm{Al} 6061-\mathrm{Al}_{2} \mathrm{O}_{3}$ and $\mathrm{Al} 7075-\mathrm{SiC}$ Composites.

The composites developed (as explained above) were subjected to hardness test using the Vicker's and Brinell's hardness testing machines. From the Figures 3 and 4, it can be observed that the hardness of composites were greater than that of its base alloy. Further, the hardness of the composite is found to increase with increased filler content.

\subsubsection{Tensile strength}

From the application point of view, the mechanical properties of the composites are of immense importance. The modified rules of mixture proposed by several researchers [59-64] are effective in predicting upper and lower bound values of the modulus and strength properties of the composites. An optimized combination of surface and bulk mechanical properties may be achieved, if Al-MMCs are processed with a controlled gradient of reinforcing particles and also by adopting a better method of manufacturing [15, 39]. Although there is no clear relation between mechanical properties of the composites, volume fraction, type of reinforcement $[5,11]$ and surface nature of reinforcements [15], the reduced size of the reinforcement particles [65] is believed to be effective in improving the strength of the composites.

The structure and properties of the reinforcements control the mechanical properties of the composites. Increase in elastic modulus and strength of the composites are reasoned to the strong interface that transfers and distributes the load from the matrix to the reinforcement [66]. Further, the improved interface strength and better dispersion of the particles in the matrix can also be achieved by preheating the reinforcements [16]. The strength of $\mathrm{SiC}, \mathrm{Al}_{2} \mathrm{O}_{3}, \mathrm{TiC}[9,38]$, and $\mathrm{TiB}_{2}$ particulate reinforced Al-MMCs is found to increase at the cost of reduced ductility, by 
increasing the volume percentage of ceramic phase and by decreasing the size of the reinforcement in the composite [65-68]. In general, the particle reinforced Al-MMCs are found to have higher elastic modulus, tensile and fatigue strength over monolithic alloys [69-72]. In case of heat treatable Al-alloys and their composites, the yield strength of composites increase after heat treatment [73] by reducing the cracking tendency [55] and improving the precipitation hardening [46]. The composites, before fabrication process, are heat treated to an under aged condition as the materials can be shaped more easily and after fabrication, these materials are heat treated to the peak aged condition so as to provide improved mechanical properties [74]. Among many ceramic materials, $\mathrm{SiC}$ and $\mathrm{Al}_{2} \mathrm{O}_{3}$ are widely in use, due to their favorable combination of density, hardness and cost effectiveness. When these reinforcements are combined with Al-MMCs, the resulting material exhibits significant increase in its elastic modulus, hardness, strength and wear resistance [75]. Further, the studies on Al-MMCs are mainly concentrated on $\mathrm{Al}-\mathrm{SiC}, \mathrm{Al}-\mathrm{Al}_{2} \mathrm{O}_{3}$ based systems with limited studies on $\mathrm{Al}-\mathrm{TiO}_{2}$ composites, though $\mathrm{TiO}_{2}$ particles have excellent mechanical properties [9, 38].

From the above, improvement in the strength of Al-MMCs can be reasoned to the presence of ceramic particles. Further, the tensile yield stress of the composites and matrix materials may be estimated, using the expression $P_{m}=c \sigma_{y}$ where $P_{m}$ is the yield pressure or hardness, $c$ is a constant having a value of about 3 and $\sigma_{y}$ is the tensile yield stress. For the Tresca's yield criterion, the shear yield stress is half of the tensile yield stress [76]. The reported literature regarding the variations of the compression strength of ceramic filled aluminum composites are meager.

\section{WEAR OF COMPOSITE MATERIALS}

Wear is the progressive loss of material due to relative motion between a surface and the contacting substance or substances [77]. The wear damage may be in the form of micro-cracks or localized plastic deformation [78]. Wear may be classified as adhesive wear, abrasion wear, surface fatigue wear and tribo-chemical, fretting, erosion and cavitation wear. Wear is a complex phenomenon in which real contact area between two solid surfaces compared with the apparent area of contact is invariably very small, being limiting to the points of contact between surface asperities. The load applied to the surfaces will be transferred through these points of contact and the localized forces can be very large. The material intrinsic surface properties, the surface finish, load, speed and temperature and properties of the opposing surfaces are important in determining the wear rate. Wear, the progressive loss of substance from the operating surfaces of the mechanically interacting element of a tribo-system may be measured in terms of weight loss or volume loss. Commonly available test apparatus for measuring sliding friction and wear characteristics in which, sample geometry, applied load, sliding velocity, temperature and humidity can be controlled are Pin-on-Disc, Pin-on-Flat, Pin-on-Cylinder, Thrust washers, Pininto-Bushing, Rectangular Flats on a Rotating Cylinder and such others. In laboratories, wear 
tests are conducted at ambient temperature by varying loads and speeds under varying environments and frictional force, wear height loss and temperature are monitored. A smaller rider of the test material was loaded against a larger moving surface and the tests were performed. The sliding may be repeated on the same counter-face or under single path conditions for which fresh tracks of the counterpart are moved against the loaded specimen.

\subsection{Factors Affecting Wear of Aluminum based Composite Materials}

The principal tribological parameters that control the friction and wear performance of reinforced Al-MMCs are mechanical and physical factors extrinsic to the material undergoing surface interaction such as the effect of load normal to the tribo-contact, the sliding velocity, the sliding distance, the reinforcement orientation, the environment, temperature, the surface finish and the counterpart and material factors intrinsic to the material undergoing surface interaction such as the reinforcement type, size, shape and distribution of the reinforcement, the matrix microstructure and the reinforcement volume fraction [79, 80]. Alpas and Zhang [81] while investigating the wear of particle reinforced MMCs under different applied load conditions identified three different wear regimes. At low load (regime I), the particles support the applied load in which the wear resistances of MMCs are in the order of magnitude better than Al-alloy. At regime II, wear rates of MMCs and Al-alloy were similar. At high load and the transition to severe wear (regime III), the surface temperatures exceed a critical value.

With regard to the material factors, the volume fraction of reinforcement $\left(v_{\mathrm{r}}\right)$ has the strongest effect on the wear resistance [82-88]. However, the variations of the wear rates of MMCs as functions of $v_{\mathrm{r}}$ are affected by the shape and size of the whiskers, fibers and particles used for reinforcement. Additionally, the effective $v_{\mathrm{r}}$, at which the wear rate reaches its minimum value, are considerably different depending on the kind of reinforcement and matrix material as well as on the sliding conditions. Therefore, it is difficult to select the type of reinforcement and volume fraction that would give optimum wear properties [5]. Many investigators carried out experiments on the wear behavior of MMCs against different counter surfaces with various test conditions. Under the following sections the effect of different parameter on the wear of MMCs are discussed.

\subsubsection{Effect of extrinsic (mechanical and physical) factors.}

\subsubsection{Applied normal load}

Applied load affects the wear rate of alloy and composites significantly and is the most dominating factor controlling the wear behavior [89]. The wear rate varies with normal load, which is an indicative of Archard's law and is significantly lower in case of composites [41]. The cumulative volume loss increases with increasing applied normal load [90-93]. Further, with 
increased applied load the contact surface temperature increases. By measuring the wear rate as a function of applied load, it has been reported [94-96] that a critical load exists below this load, where the wear rate is mild and steady; above this load a severe wear rate occurs and the critical load decreases with temperature [27]. If the load is further increased, then the unreinforced and reinforced composites eventually seize. The seizure event was accompanied by a sudden increase in wear rate, heavy noise and vibration. This type of seizure has been referred to as galling seizure [17]. As the wear rate increases with increased applied load, the wear mechanism reported was oxidation at lower loads and adhesion and delamination at higher loads [97]. The specific wear rate of Al-alloy was reported to have decreased with increase in the applied load. Al-alloy easily undergoes thermal softening and re-crystallization at higher temperature compared with the composites because the strength of the composites at higher temperature is greater. As a result, the wear rate of the Al-alloy is increased drastically at higher loads. At low loads, as particles act as load bearing constituents, the direct involvement of Al-alloy in the wear process is prevented [66]. Metallographic observations at low loads indicated that there was less chemical interaction of the composite with the counter-face due to smaller true contact area [96]. The wear debris size is of the order of millimeters at higher load while at the lower load, it is of the order of a few hundred micrometers [40]. As the load increased, the proportion of metallic wear debris increased and the size of the delamination increased for the composite. At the highest load, the worn surface of the materials could be described as classical rachetting wear, as defined by Kapoor et.al [96]. The transition in wear rate observed for many MMCs is faster and test temperature dependent and is believed to be the result of voiding/cracking between reinforcement and the matrix [50], both of which lead to fragmentation and delamination of the surface. Thus, the maximum load a composite can support during sliding without excessive wear can be obtained by the fracture toughness values of the reinforcement [98].

\subsubsection{Sliding speed/velocity/distance}

With the increase of sliding speed/velocity/distance, the wear rate and cumulative wear loss increases for all the materials [99] and the curve trend may be linear [40, 41]. The sliding speed influences the wear mechanism strongly and at low sliding speed, the wear rate of the composites is lower. This may happen because at high speed, the micro thermal softening [100] of matrix material may take place, which further, lowers the bonding effect of the reinforced particles with that of matrix material [28]. At higher sliding velocity, wear rate is lower for MMCs and is due to the formation of a compact transfer layer at the region of the worn surfaces. The amount of the constituents of the counter-body in the transfer layer is seen to increase as sliding velocity increases thus forming a protective cover which tends to reduce wear rate [101]. Kowk and Lim [102] report that massive wear occurs if the particles are smaller than a threshold value at higher speeds. 


\subsubsection{Effect of temperature}

The wear volume increases $[69,91]$ substantially above a characteristic temperature that exists between the mild and severe wear transition. Mild to severe wear occurs when friction-induced heating raises the contact surface temperature above a critical value [17] (at about 0.4 times the absolute melting temperature of the matrix). The composite transition temperature is higher than that of the unreinforced alloy thus the composite suffers lower wear volume. The higher the normal pressure, the lower is the transition temperature [103]. The higher thermal conductivity of the reinforcement contributes in improving wear resistance [104, 105].

\subsubsection{Surface finish and hardness of counterpart}

Surface roughness affects the wear rate. The higher the roughness, the higher will be the wear rate [78]. The counter-face hardness is inversely proportional to the wear rate thus the counter material with a lower hardness reduces the wear resistance due to the mutual abrasion between the counter material and the wear surface of the specimen [90]. Wear of the counter-face depends on the mechanism of wear of the composite. An increase in load generally results in an increased wear rate of both the composite pin and counter-face. Increasing the volume fraction of particles in the composite reduces its wear rate but increases the wear rate of the counter-face, thus when both counter-face and composite wear are considered, an optimum volume fraction of particles exists at which wear is lowest [39].

\subsubsection{Nominal contact area}

Yang [106] indicated the dependency of the wear coefficient and wear rate on the nominal specimen contact area; a smaller nominal specimen contact area will yield a smaller wear coefficient value, as the wear asperity volume available is smaller. It should also be observed that, generally, an increase in load or sliding speed also increases the volume loss and consequently the wear coefficient. From the literature, it can be concluded that the wear coefficient values obtained from the pins with a smaller nominal contact area were indeed lower by an average of about $12 \%$ than the larger ones, due to the availability of smaller asperity wear volumes. Hence one should exercise extreme care in the interpretation of wear coefficient data obtained from different testing methods or the use of different nominal specimen contact areas.

\subsubsection{Effect of intrinsic (material) factors.}

\subsubsection{Reinforcement size and shape}

Several investigators have proposed that wear resistance of a material depends on its hardness, strength, ductility, toughness, the kind of reinforcement, its volume fraction $\left(V_{\mathrm{f}}\right)$ and the particle 
size [107-115]. The particle reinforcements are the most effective in improving the wear resistance of MMCs [116] provided that good interfacial bonding between the reinforcement and the matrix exists.

The wear resistance of the composites is improved by preventing direct metallic contacts that induce subsurface deformation [117]. The addition of hard ceramic particles improves the resistance to seizure at elevated temperatures. The particulate allow considerable thermal softening effects without having adverse effects on the wear behavior [30]. The reinforcement also causes higher hardness, superior elastic modulus, greater dynamic modulus, better damping capacity and less coefficient of thermal expansion of the matrix alloy [118-121]. The presence of the ceramic particles provides a higher thermal stability, increased abrasion [9] and sliding wear resistance at high temperature and also delays the transition from mild to severe wear [31,69].

It is found that the wear rate decreases with decrease in the grain size. This can be attributed to the grain boundary strengthening of Al leading to strain hardening. Such behavior may be attributed to the change in the grain shape from equiaxed to columnar ones [122]. The reinforcement particles with size of several micrometers have higher bonding strength with the matrix, which support the applied load effectively and prevent the crack to initiate and propagate in the subsurface wear region. Therefore, the wear resistance of the composites is improved significantly [68]. The predominant friction mechanism at particulate sizes below $13 \mu \mathrm{m}$ involved adhesion and micro ploughing, these being augmented by hard third body $\mathrm{SiC}$ abrasion with increasing particulate size. Adhesion and micro cutting were the predominant wear mechanisms for smaller reinforcements, the higher wear rates observed in the larger particulate reinforced composite tribo-system being associated with increased particulate cracking-induced subsurface de-lamination [123].

Zum Gahr [124] emphasized the role of second phase particles in providing localized areas of high stress concentrations that influenced flow stress and wear rate. The highest wear resistance was obtained in microstructures associated with fine, well-dispersed semi-coherent particles. For materials characterized by carbides, dispersed in a soft matrix, a decrease in the particle mean free path by reducing the carbide size resulted in improved wear resistance. The wear resistance of composites, compared to the alloys, was attributed to their favorable distribution of particles of a relatively small size [46].

The main concern about Al-MMCs is that, larger the volume fraction and finer the size of the reinforcement, expensive are the MMCs. Hence, there is a need to reduce the cost component by optimizing its volume fraction and avoiding/minimizing the use of finer particles [93]. The reinforcement of fine $\mathrm{Al}_{2} \mathrm{O}_{3}$ particles strengthens the Al-matrix and enhances the wear resistance [57]. The residual alloy phase and the presence of a rigid ceramic skeleton enable the blunting or lubricating properties of the alloy in producing good tribological properties [125]. 


\subsubsection{Effect of different types of reinforcements}

The $\mathrm{SiC}$ reinforcement in the Al-MMCs is more fracture resistant compared to $\mathrm{Al}_{2} \mathrm{O}_{3}$ and $\mathrm{Si}$. The $\mathrm{SiC}$ particles are harder than other reinforcements and will provide a more effective barrier to subsurface shear by the motion of the adjacent steel counter-face $[9,30]$ and this result is likely due to differences in particles shape [32]. An additional drawback of Al-MMCs with reinforcing phases, such as $\mathrm{SiC}$ and $\mathrm{Al}_{2} \mathrm{O}_{3}$ is the tendency of the reinforcement to act as a second-body abrasive against the counter-face increasing its wear rates [66]. In addition, reinforcement liberated as wear debris acts as a third-body abrasive to both surfaces. The two effects result in a higher wear rate for the system as a whole when MMC is used compared to the monolith, while the extent of this problem depends on the mechanical properties of the counterface material [96].

The presence of iron oxide debris in the wear track plays an important role as it has been reported to be beneficial in reducing the resistance to friction for MMCs reinforced with $\mathrm{Al}_{2} \mathrm{O}_{3}$ or $\mathrm{SiC}$ particles sliding against steel [126]. The debris for mild wear mainly consisted of ferric oxide $\left(\mathrm{Fe}_{2} \mathrm{O}_{3}\right)$, while the debris for severe wear was composed of $\mathrm{Al}_{2} \mathrm{O}_{3}, \mathrm{Al}, \alpha-\mathrm{Fe}$ phases. Moreover, the addition of $\mathrm{Si}-\mathrm{Fe}$ eutectic alloy and $\mathrm{Al}_{2} \mathrm{O}_{3}$ particles increased the transition load from mild to severe wear of A12024 alloy by more than three times and decreased the coefficient of friction [127].

Incorporation of $\mathrm{TiO}_{2}$ particles resulted in the wear of disc. The $\mathrm{TiO}_{2}$ particle appears to reduce both plastic flow in the matrix and the metal transfer to the pin [40]. The TiC-reinforced Al356 alloy was the hardest and exhibited the lowest wear rate and an increase in the load at which the transition from low wear rate to high wear rate occurs [108]. An addition of granite particulate to Al6061 showed that it not only delays the transition wear but also reduces the wear rate and coefficient of friction [33]. The experimental results have shown a significant enhancement in the wear resistance of $\mathrm{B}_{4} \mathrm{C}$ particle reinforced A15083 MMCs [106]. Cryogenically treated composites may show considerable reduction in the wear rate with an increase in hardness and strength at higher applied loads [92]. The $\mathrm{MoSi}_{2}$ and $\mathrm{Cr}_{3} \mathrm{Si}$ reinforced alloys $(2124,5056)$ exhibited the lowest specific wear rates [128]. The wear resistance of the composites improved by incorporating $\mathrm{TiB}_{2}$ particle reinforcement and the refinement of the matrix grains greatly improved the mechanical properties of the composites [40]. Further, the $\mathrm{TiB}_{2}$ particles markedly improve the wear performance of the $\mathrm{Al}-4 \mathrm{Cu}$ alloy. It can be said that $\mathrm{TiB}_{2}$ particles not only protect the matrix by virtue of their high hardness but also by generating the fine iron rich debris which acts as an effective lubricating medium [129].

\subsubsection{Effect of reinforcement volume fraction}

It has been reported that the wear resistance of composite increases with increase in volume fraction of the reinforcement [109-113]. The wear resistance of MMCs can be improved by 
increasing the volume fraction of the reinforcing ceramic phase by as much as $70 \%$ [114]. Also the dry sliding wear resistance increases with increase in particle volume fraction. At higher volume fraction, the friction coefficient was found higher and there was almost no effect of load on friction coefficient [80].

The wear rates of the counter-face material increased with increase of volume fraction of the ceramic particles. This is mainly due to the fact that the hardness and strength of composites are higher and they increased with increase in filler content [57]. The volumetric wear rate increased with increasing applied load while it decreased with increasing volume fraction of the filler material [97]. This may be due to the reason that addition of ceramic content resulted in a pronounced drop in ductility $[130,131]$ accompanied by an increase in hardness which may further increase the wear resistance of the composites. At any constant load, wear rate decreases with increase in addition of $\mathrm{SiC}_{\mathrm{p}}$ and improves the load bearing properties of $\mathrm{Al}$-alloy during sliding. Increase in the addition of $\mathrm{SiC}$ restricts the flow or deformation of the matrix material with respect to load [90].

The cumulative volume loss and the wear rate decreases linearly with increasing volume fraction of Titanium Carbide (TiC) in pure Al. Average coefficient of friction also decreases linearly due to a protective cover provided by transfer layer with increasing volume fraction of $\mathrm{TiC}$ [38]. Increase in volume fraction of $\mathrm{TiC}$ increases the wear rate of the counter-face. Hence it is suggested that when both counter-face and composite wear are considered, an optimum volume fraction of particles exists at which wear is lowest [39].

\subsubsection{Effect of interfacial bonding}

The wear behavior of hard particle reinforced composite depends primarily on the type of interfacial bonding between the Al-matrix and the reinforcement. This is because of the strong interfacial bond which plays a critical role in transferring loads from the matrix to the hard particles, resulting in less wear of the material. In case of poor interfacial bonding, the interface offers site for crack nucleation and tends to pull out the particle from the wear surface tending to higher wear loss [8]. For ex; the $\mathrm{Ni}$ and $\mathrm{Cu}$ coated $\mathrm{SiC}$ dispersed $\mathrm{Al}-\mathrm{SiC}$ composites generally lead to good quality interface characteristics and exhibit the improved wear properties $[55,132]$.

\subsubsection{Effect of porosity}

The wear rate of insitu composites containing relatively lower reinforcing particle increases gradually with increasing volume fraction of porosity up to critical porosity value of about 4 vol.\%, but beyond that level, wear rate increases more rapidly. This could be attributed to its combined effect on real area of contact and subsurface crack propagation. Also, the wear coefficient increases considerably with increasing porosity content in this group of cast in situ 
composite. Sometimes, the contributions of the reinforcing particles in enhancing the wear resistance have been obliterated by increased porosity content and therefore, it should be controlled in cast insitu composites. However, a limited amount of porosity could be tolerated in cast insitu composites without impairing its wear resistance significantly.

The wear rate of the cast insitu composites containing relatively lower porosity decreases continuously with increasing particle content, more than expected on the basis of decreasing real area of contact. It is, therefore, expected that blunting of subsurface cracks at porosity could decrease wear debris generation as indicated by decreasing wear coefficient with increasing particle content at lower level of porosity [41].

\subsubsection{Effect of wettability}

It can be concluded that wettability of the reinforcement in the matrix and interfacial strength are related to one another vis-a-vis micro-hardness value, coefficient of friction and wear property of metal matrix composite. The decrease in the coefficient of friction value and increase in the wear resistance are due to better distribution of the particle in the matrix, which is due to the improvement in the wettability of the reinforcing phase with the matrix [133]. For ex; to improve surface wetting during casting, the graphite particles were coated with a nickel [134].

\subsection{Effect of Lubrication}

Concerning wear mechanisms under lubricated conditions, the degree of direct contact between the surfaces is minimal and the wear progresses via layers of debris [11]. For all materials, wear loss in lubricated tests at constant load decreases as hardness increases. However, for lubricated conditions, Al-MMCs with higher hardness show higher wear resistance [135].

Scuffing and seizure problems may be addressed by incorporating solid lubricants, namely, Graphite in $\mathrm{Al}-\mathrm{Si}$ alloys reinforced with $\mathrm{SiC}$ or $\mathrm{Al}_{2} \mathrm{O}_{3}$ particles [136]. It was shown that the addition of graphite flakes or particles in Al-alloys increased the loads and velocities at which seizure took place under the boundary lubricated [137, 138] and dry sliding conditions [139, 140]. The high seizure resistance of graphitic Al-matrix composites has been attributed to the formation of graphite layers on the contact surfaces that act as solid lubricants, which reduce metal to metal contact between the sliding pairs [141, 142]. One more important factor is that the lubricant used will act as a coolant between the two sliding surfaces avoiding the consequences of increasing temperature of the metals in contact.

\subsection{Effect of Load \& Work Hardening}

In case of alloy, rate of work hardening might be higher and also there is every possibility of entrapment of loose abrasives in the matrix, resulting in relatively reduced wear rate in alloy as 
compared to the composite with increasing load. In case of abrasive wear, the overall effect of abrasive size on wear rate becomes significantly less as compared to the contribution of load when the matrix of the composite is already subjected to a certain amount of strain hardening effect before being subjected to wear. [89].

Decreasing wear rate with sliding distance is a definite indication of more effectiveness of work hardening of the subsurface regions due to increasing wear induced plastic deformation. Subsurface hardening was evidenced by increased hardness in the subsurface region as compared to the unaffected bulk [143].

With the repeated dry sliding test, a working hard layer occurs on the wear surface and this promotes wear resistance of the composites. At the same time, the wear surface temperature increases subsequently. As a result, re-crystallization takes place in the worn surface during the dry sliding, which results in the decrease of the wear surface hardness and this considerably counteracts the promoting effect of the wear resistance by work hardening. Moreover, the oxidization layer formed on wear surface of the sample is beneficial in enhancing the wear resistance [68].

\subsection{Effect of Mechanical Mixed Layer (MML)}

During sliding at higher wear-rates, high temperature is developed at the sliding surface due to which the specimen softens and becomes plastic. It reacts with the available oxygen and forms their respective oxides. The hard brittle oxide formed on the surface of the specimen becomes thicker and continuous, covering the entire surface. The Aluminum oxide film acts partly as an insulator for thermal conduction. This MML was responsible for the decrease in the wear-rate and friction of the MMCs [144]. The transfer of steel inclusions from counter-face surfaces to the composite wear surfaces is another mechanism which contributes to the increase in wear resistance of the composites [145]. This indicates that the inclusions act as additional reinforcements at the wear surface of composite and are load supporting [30] and the specific wear rate decreased with increasing MML thickness [144]. The MML forms on the worn surface of matrix and composite and it serves as a protective layer [80,97] and a solid lubricant. In composites having low volume fraction, the MML is stable under low loads and unstable under higher loads. In the composite having higher volume fraction of reinforcement, the MML is stable under high loads [146]. The MMLs were formed in the worn surfaces at a variety of sliding loads. The mixed layers had micro-structural features comprising of a mixture of ultrafine-grained structures in which the constituents varied depending on the sliding loads [147]. Venkataraman et.al found that the thickness of the transfer layer increases as the normal load increases [148]. Due to the presence of MML, the wear rates of both the pin and disc are lower at higher speeds. With increasing speed the amount of layer formation increases due to the higher temperatures generated [146]. The extent of cover provided by this transfer layer is determined 
by the load, sliding speed and environmental conditions and it increases with increasing load because of the increased frictional heating and hence, better compaction [149, 150].

Once the MML is formed, it provides a surface protection before critical conditions are reached and then loose debris gets detached from the mixed layer, in agreement with the wear behavior observations that the wear rate was lower at an intermediate load range with presence of the MML. The MML was not uniform in thickness across the entire wear track and it actually exhibited a wavy shape in the cross section of the worn surface. The wear rate, thus, would be influenced by the formation and detachment of the MML in the load range used [147]. Formation of the tribo-layer delays the mild to severe wear transition in Al-MMCs. Once the tribo-layer is removed from the contact surface, the bulk material comes in direct contact with the counter-face and it is difficult to form a new tribo-layer on the hot and softened matrix [26]. On further sliding, the MML gets separated out from the pin surface due to delamination leaving behind the fresh pin surface, which results in the drop of frictional force [122]. The results indicate that different type of reinforcement can generate MMLs. The observations indicate that the MML formed with material comes from three sources; the counter-face (contributing with Fe, about $20 \% \mathrm{Fe}$ ), the matrix and the particles [148].

Some characteristics of the MML, which can be used to distinguish it from the normal composite material, are: (a) a darker color than the normal composite material when observed under optical microscope. (b) The presence of chemical elements coming from the counter-face. (c) A higher micro-hardness value in the MML and abrupt change to too much lower values outside the MML [23]. The hardness of the MML was found to be much harder than that of the matrix hardness in the composite [26]. Actually, the hardness of the MML is independent of the composite and the value is comparable to the hardness of the steel counter-face. It is noted that the MML is not formed in the non-reinforced material, mainly because no trace of iron was found on the worn surface [148]. Micro-hardness studies along the vertically sectioned surface starting from the worn surface show that the magnitude of the hardness of the specimen decreases with the distance from the worn surface, which indicates that the sub-surface nearer to the worn surface was hardened due to strain hardening effect than the region away from the worn surface.

$\mathrm{Li}$ and Tandon [151] were among the researchers who have reported the formation of iron-rich oxidized tribo-layers on the contact surfaces. Detailed investigations of the tribo-layers on the Al-Si alloy worn surfaces were also presented by Biswas [152]. The transition between the mild and the severe wear regimes were attributed to the removal of these layers [153]. Almost all the investigations performed to date on the formation of tribo-layers and material transfer phenomena accompanying sliding wear of Al-Si alloys were conducted in an ambient atmosphere as a function of applied normal load and sliding speed. The $\mathrm{SiC}$ undergoes tribochemical interaction during sliding and forms $\mathrm{SiO}_{2}$, which acts like a lubricant, especially at higher speeds [146]. 
The protection cover provided by MML is observed to increase with increasing volume fraction of TiC. This may be attributed to the higher hardness of the substrate having relatively higher amount of $\mathrm{TiC}$, which is able to hold a thicker transfer layer of compacted oxide as compared to the substrate of lower hardness $[149,150]$. When the reinforcement in the matrix has wide size distribution, wear rate and friction coefficients are found to be higher compared to composite containing mono-size reinforcement [80].

\subsection{Effect of Heat Treatment}

The alloy and composites exhibit minimum wear rate after heat treatment due to improved hardness [57]. In case of cast alloy, the value of wear constant was higher than that of the heattreated alloy and composite. During the wear process, the cracks are mainly nucleated at the matrix and reinforcement interfaces. Heat-treated alloy and composite showed better strength and hardness that resulted in fewer propensities for crack nucleation and showed enhancement in wear resistance [46, 55]. In case of heat-treated alloy, the effective stress applied on the composite surface during wear process is less due to higher strength and ductility of the Al matrix. This resulted in less cracking tendency of the composite surface as compared to the cast alloy [55]. The heat treatment did not radically change the morphology but hardening of the matrix by precipitation hardening took place, which led to higher hardness and strength [46].

The highest wear resistance was obtained for T6 thermal treatment condition. The studies have determined that the maximum hardening of the matrix was obtained when the composite material was solubilied at a temperature of $560^{\circ} \mathrm{C}$ for 3 hours, quenched in ice water at $0^{\circ} \mathrm{C}$ and ageing done at a temperature of $175^{\circ} \mathrm{C}$ for 7 hours. It was found that the heat treatment $\mathrm{T} 67$ hours was the one that provided the matrix greater hardness and therefore it was the one, which gave the MMC the higher wear resistance [154]. The higher hardness and yield strength of the composite by T6 heat treatment would have the advantage of preventing the formation of aluminum debris and decreasing its transfer to the surface of steel [155]. When aged at the lowest temperatures (between $50-150^{\circ} \mathrm{C}$ ), the hardness and abrasive wear resistance of under-aged composites were found to be relatively low. Raising the ageing temperature to $200^{\circ} \mathrm{C}$ increased the hardness and abrasion resistance of the composites to the peak-aged condition. At $250^{\circ} \mathrm{C}$ the composites were over-aged and this resulted in a reduction in hardness and wear resistance due to the coarsening of the inter-metallic precipitates [56]. Decreasing the discontinuously reinforced aluminum (DRA) matrix strength through under-aging and over-aging heat treatments decreases the DRA wear rate under abrasion conditions by enhancing the formation of a protective solid film [123]. 


\section{MODELS FOR PREDICTION OF WEAR PROPERTIES}

In automobile, aerospace, mining and mineral sectors, there exist situations where two mating parts are in sliding contact with each other. Due to the relative motion of these sliding parts, there is an inevitable loss of material. In certain situations, if the extent of material wear is beyond a critical limit, there are possibilities of catastrophic failure of the components leading to huge economic losses. Extensive research has been carried out on the study of tribological behavior of Al-MMCs [156]. The most important reason for the damage and consequent failure of machine parts is wear. A lot of experiments must be conducted in order to study the tribological behavior. This results in wastage of both man power and money [157]. Hence the prediction of wear rate is of utmost importance in the present industrial scenario to assess the life of sliding components in advance to avoid massive financial losses that are incurred due to wear.

\subsection{Prediction of Wear Properties by Theoretical Models}

Yang has proposed a new formulation of the wear coefficient that was developed and tested experimentally, which was based on exponential transient wear volume equation and Archard's equation. The wear equation was found to be a better predictor of steady state wear coefficients [25]. Sharma developed a theoretical model for estimating the sliding wear rate considering the effect of frictional heat on the wear properties at contact surfaces, the effect of reinforcement, mechanical load, sliding distance, sliding velocities on wear rates, coefficient of friction and transition wear. This theoretical model was proposed for estimating the sliding wear rate of both alloy and composites [33]. Kumar et.al., have successfully developed a mathematical model to predict the wear rate of Al7075-SiC composites by incorporating the effects of volume fraction, reinforcement size, applied load, sliding speed and hardness of the counter-face material. The developed model can be effectively used to predict the wear rate of A17075-SiC composites at 95\% confidence level [90]. Das et.al., correlated wear behavior of Al-alloy and composites in terms of mechanical properties, micro-structural characteristics, applied load and abrasive size through an empirical equation; which, demonstrated the effect of size and volume fraction of reinforcing phase and the size of the abrasive particles on the wear rate of Al alloy and composites. It suggests that the wear rate of the composite will increase with increase in size of reinforcing phase and the composite may suffer higher wear rate than the alloy if the abrasive size is higher than that of reinforcing phase [57].

Sahin developed wear resistance model for the MMCs based on the Taguchi method. The orthogonal array, signal-to-noise $(\mathrm{S} / \mathrm{N})$ ratio and analysis of variance were employed to find the optimal testing parameters. The results showed that the abrasive grain size was the most powerful factor on the abrasive wear, followed by weight fraction of reinforcement. Optimal wear testing conditions were verified with an experiment. It was observed that there was a good agreement between the predicted and actual wear resistance for a 95\% confidence level [158]. Mondal et.al., predicted the wear behavior through statistical analysis of the measured wear rate 
at different operating conditions. The wear rate is expressed in terms of the abrasive size and applied load by a linear regression equation. Factorial design of experiment can be successfully employed to describe the high stress abrasive wear behavior of Al-alloys and composites and to develop empirical linear regression equations for predicting wear rate within a selected experimental domain [89]. Further, few researchers also made an attempt to evaluate the wear coefficients by using Archard's and Yang's theoretical models and concluded that the predicted values of the wear coefficient are in close agreement with the experimental ones [159].

\subsection{Prediction of Wear Properties of Composites by Soft Techniques}

Recent progress in informatics and high capability computing devices has offered a brand new springboard for the engineering community to reshuffle its traditional R\&D criteria. Particularly, artificial intelligence (AI), an information processing technique, exhibits outstanding effectiveness in accommodating the highly demanding requirements of new generation problems. AI serves as a powerful solution to complex engineering problems, for which conventional straightforward logical algorithms are usually inefficient. Several variants originating from fundamental AI concept can be found in application, namely expert system, fuzzy logic, inductive learning, genetic algorithms and Artificial Neural Network (ANN).

ANN can be customized and trained using a series of typical inputs and their corresponding expected outputs, to establish an implicit non-linear and multi-dimensional correlation between them while avoid exploring the constitutive relation for a complicated system. Inherently endowed with talents in adaptability, robustness and parallelism, the ANN technique has found substantial applications in pattern recognition, classification, functional approximation and signal processing and system identification [160]. Inspired by the biological nervous system, the ANN approach is a fascinating mathematical tool, which can be used to simulate a wide variety of complex scientific and engineering problems. ANN can be customized and trained by using a certain amount of experimental data to a well designed ANN. After the network has learnt to solve the material problems, new data from the similar domain can then be predicted without performing too many long experiments [161]. ANN helps in reducing the cost of experimentation when implemented with care and enough data.

Recently ANNs have received a great deal of attention as a prediction and modeling tool in many research areas. ANNs can be defined as massively parallel distributed processors, which have a natural tendency to store experimental knowledge and make it available to use [162]. ANN uses interconnected nodes called neurons where inter-connections are weighted to mimic the ability of human brain and to learn from experience and find solutions for complex nonlinear, multidimensional functional relationships. The main characteristic of the network is that the network describing the relationship is trained directly by examples without any prescriptive formulae about the nature of the problem. The ANN method is suitable when (i) large database is 
available, (ii) it is difficult to find an accurate solution for a problem by mathematical approaches, (iii) the data set is incomplete, noisy and complex [163].

There are a number of ANN topologies. The differentiating criteria include the way information flows through the network (e.g. feedback/feed-forward) and the method used to optimize the model coefficients. The feed-forward and recurrent networks are suited to prediction and forecasting applications. Recurrent networks are perceived to have a number of advantages over feed-forward networks, especially in time series applications. However, recurrent networks do not have any advantage over feed-forward networks in which time structure is accounted for explicitly in the model inputs. It should be noted that the processing speed of feed-forward networks is better than recurrent networks. In addition, they have been found to perform well in comparison with recurrent networks in a number of real life applications.

The model parameters in recurrent and feed-forward networks are generally estimated using a 'supervised' algorithm, the aim of which is to minimize the error between the model outputs and corresponding historical values. This process may be viewed as a highly nonlinear optimization problem and a number of optimization techniques are applicable. Traditionally, the backpropagation algorithm has been used, which is based on the method of steepest descent. In the vast majority of papers that deal with the prediction and forecasting of environmental variables, feed-forward networks optimized with the aid of the back-propagation algorithm (known as back-propagation networks) have been used [164]. ANNs were traditionally used to replicate tasks which are performed well by the human brain, including recognizing handwritten characters, contour recognition, texture recognition, face recognition and classifying twodimensional shapes. However, the number of uses for ANNs is expanding rapidly and in recent years, an increasing number of engineers and scientists have been considering the use of ANNs for environmental modeling in preference to more conventional statistical techniques. This is because they are non-linear, relatively insensitive to data noise and perform reasonably well when limited data is available. In addition, the statistical distribution of the data used does not have to be known and they can cater for cyclic and seasonal variations in the data. They have already been successfully used to assess the effect of climatic change on river hydrology and ecology and to predict salinity, incidences of blue-green algae, nutrient concentrations, ozone dosage, algal concentrations, sea surface temperatures, rainfall, rainfall-runoff and the density of brown trout spawning [164].

ANNs are generally used by engineers and scientists to capture relationships between environmental data and to help provide a better understanding of environmental phenomena. However, as ANNs are a relatively recent addition to the toolkit of environmental modelers, they are generally not well understood and current and potential users tend to treat them as 'black box' models. In addition, "there is a tendency among users to throw a problem blindly at a neural network in the hope that it will formulate an acceptable solution. In the model development 
phase, ANN operation and the effect of a number of internal parameters are often ignored. This can result in inferior model performance and an inability to compare accurately the performance of different ANN models [164].

Rasit Koker et.al. [162] used ANN model for the prediction of mechanical properties of particulate reinforced MMCs and concluded that the ANN model with three layer feed forward structure with the Levenberg-Marquardt (LM) training algorithm gave better and faster results than other algorithms. Rao et.al. [165] confirmed that the ANN model serves as an effective, simple, fast, efficient and compact tool which can simulate the stress-strain response and predict the amount of debonding at the interface for ceramic-matrix composite. Cavaliere [166] reported that an ANN of basic structure with back propagation (BP) algorithm and a bi-polar sigmoid activation function for hidden and linear activation function for output layers could predict flow curves of MMC. A 3 layered BP network which is an effective tool to predict parameters with non-linear relationships could predict density, porosity, hardness, tensile strength, flexural strength, toughness, roughness of machined surface, flow stress and solid particle erosion with a reasonable accuracy [167-174]. It was reported that ANN network showed excellent performance in predicting wear volume loss, specific wear rate and friction coefficient as a function of sliding speed and load for different compositions of fiber and particulate reinforced composites [175, 176]. Raimundo Carlos et.al. [177] used ANN approach in modeling and building of constant life diagrams, using a small number of $\mathrm{S}-\mathrm{N}$ curves in the training set. Based on the results, they concluded that the ANN having gating network has given more reliable results. Rashed et.al. [178] applied ANN technique to study the effect of size and weight percent of SiC particulates, applied pressure and test temperature on the wear resistance of A1356-SiC MMCs and have shown that ANN is an effective tool in the prediction of the properties of MMCs and is found more useful compared with time-consuming experimental processes. Several researchers have developed ANN models using Matlab software. From the above, it can be concluded that ANN can be successfully implemented for the prediction of mechanical and tribological properties of various composite materials. A well trained ANN model can be used to predict any new data from the same knowledge domain thus avoiding repetition of long-term experiments, wastage of manpower and money [179-182].

\section{CONCLUDING REMARKS}

This review presents the views, experimental results obtained and conclusions made over the years by numerous investigators in the field of particle reinforced Al-MMCs. A considerable amount of interest in Al-MMCs evinced by researchers from academics and industries has helped in conduction of various studies and has enriched our knowledge about the physical properties, mechanical properties and tribological characteristics. Several techniques are followed by researchers for the processing of particulate reinforced MMCs. 
$>$ It has been studied and concluded that the density of the composites increases with the incorporation of the hard ceramic reinforcement into the matrix material. In view of the above conclusions on density, experiments were conducted on the A16061-SiC and A17075$\mathrm{Al}_{2} \mathrm{O}_{3}$ to determine the density by weight to volume ratio and by rule of mixture. The experimental and theoretical densities of the composites were found to be in line with each other. There is an increase in the density of the composites compared to the base matrix.

The hardness of the composites was reviewed and on conclusion, it is discovered that as the reinforcement contents increased in the matrix material, the hardness of the composites also increased. Further, the tests conducted to determine the same indicated the (Vickers and Brinell's hardness) increased hardness with increased reinforcement contents when compared with the base matrix. The mechanical properties were reviewed with respect to strength. It is evident that the structures and properties of the reinforcements control the mechanical properties of the composites. The reported literature regarding the variations of the compression strength of ceramic filled aluminum composites are meager.

$>$ The wear performance of hard ceramic reinforced aluminum matrix composites was reviewed with particular emphasis on the mechanical and physical factors and material factors also with the effect of lubrication, work hardening, Mechanical Mixed Layer, heat treatment etc. All the factors have considerable effect on the tribological performance of AlMMC and counterface metal couples. From the literature it can be concluded that the ceramic reinforced Al-MMCs will have better wear resistance than the unreinforced alloys. Further, the techniques used by the researchers to predict the wear coefficient were also discussed.

Finally there is an immense potential, scope and opportunities for the researchers, in the field of prediction of mechanical and tribological properties of the particulate reinforced metal matrix composites by using soft computing techniques.

\section{ACKNOWLEDGEMENTS}

The authors express their thanks to Dr. R. Chenraj Jain, Chancellor, Jain University, Prof. T.S. Sridhar, Director, Dr. Y. Vijay Kumar, Principal, Dr. Ananda Bukkambudhi, Professor and Head, Department of Mechanical Engineering and to Prof. R. Suresh Kumar. Assistant Professor, Department of Mechanical Engineering, S B M Jain College of Engineering, for their support and encouragement during the research studies.

\section{REFERENCES}

[1]. R. Dwivedi, "Performance of MMC Rotors in Dynamometer Testing", SAE Technical Paper Series, 940848, Warrendale, PA, USA. 
[2]. B. Neitzel, M. Barth, M. Matic, "Weight Reduction of Discs Brake Systems with the Utilization of New Aluminum Material”, SAE Technical Paper Series, 940335, Warrendale, PA, USA.

[3]. T. Zeuner, P. Stojanov, P.R. Saham, H. Ruppert, A. Engels, "Developing trends in disc brake technology for rail application”, Mater. Sci. Technol. 14 (1998) 857-863.

[4]. R. Dwivedi, "Development of Advanced Reinforced Aluminum Brake Rotors", SAE Technical Paper Series, 950264, Warrendale, PA, USA, 1995, 8 p.

[5]. T. Miyajima, Y. Iwai; "Effects of reinforcements on sliding wear behavior of aluminum matrix composites", Wear 255 (2003) 606-616.

[6]. Mortensen A, Wong T. Metall Trans A; Vol 21 A: pp 2257-63.

[7]. Y.M. Pan, M.E. Fine, H.S. Chang, "Wear mechanism of aluminium based meal matrix composite under rolling and sliding contraction in technology of composite materials", P.K. Rothagi, P.J.B. Ian, C.S. Yune (Eds.), ASM International, 1990, pp. 93-101.

[8]. S.V. Prasad, P.K. Rothagi, "Tribological properties of Al alloy particle composite”, J. Metall. 39 (1987) 22.

[9]. Kassim S. Al-Rubaie, Humberto N. Yoshimura, Jose Daniel Biasoli de Mello, "Twobody abrasive wear of Al-SiC composites", Wear 233-235 (1999) 444-454.

[10]. L. Ceschini, C. Bosi, A. Casagrande, G.L. Garagnani, "Effect of thermal treatment and recycling on the tribological behaviour of an AlSiMg-SiCp composite", Wear 251 (2001) 1377-1385.

[11]. M.D. Bermudez, G. Martinez-Nicolas, F.J. Carrion, I. Martinez-Mateo, J.A. Rodriguez, E.J. Herrera, "Dry and lubricated wear resistance of mechanically-alloyed aluminum-base sintered composites", Wear 248 (2001) 178-186.

[12]. H. Y. Sohn, S. PalDey, "Synthesis of ultrafine particles and thin films of Ni4Mo by the vapor-phase hydrogen coreduction of the constituent metal chlorides", Materials Science and Engineering A, Vol- 247, Issues 1-2, (1998), Pages 165-172.

[13]. D.M. Aylor, Metals Handbook V-13, vol. 9, ASM Metals Park, OH, 1982, pp. 859-863.

[14]. N. Wang, Z. Wang, G.C. Weatherly, "Formation of Magnesium Aluminate (spinel) in Cast SiC Particulate-Reinforced Al(A356) Metal Matrix Composites”, Metallurgical and Materials Transactions A, 23 (1992) 1423-1430.

[15]. H. Ribes, M. Suéry, G. L'Espérance, J.G. Legoux, "Microscopic examination of the interface region in 6061-A1/SiC composites reinforced with as-received and oxidized $\mathrm{SiC}$ particles", Metallurgical and Materials Transactions A, 21 (1990) 2489-2496.

[16]. Sanjay Kumar Thakur, Brij Kumar Dhindaw, "The influence of interfacial characteristics between $\mathrm{SiCp}$ and $\mathrm{Mg} / \mathrm{Al}$ metal matrix on wear, coefficient of friction and microhardness", Wear 247 (2001) 191-201.

[17]. Daoud A., M.T. Abou-Elkhair, P. Rohatgi, "Wear and friction behavior of near eutectic Al-Si+ZrO2 or WC Particle Composites”, Compo., Sci., and Tech., 64 (2004) 10291040 . 
[18]. V.V. Bhanu Prasad, K.S. Prasad, A.K Kurovilla, A.B. Pandey, B.V.R.Bhat and Y.R Mahajan, "Composite strengthening in 6061 and Al-4 Mg alloys", Journal of Mat., Sci., 26 (1991) 460.

[19]. Y. Wu and E J. Lavemia, Prec. Conf. Advancements in Synthesis and Processes, Toronto, Oct 20-22, 1992, Society for Advancement of Material and Process Engineering, 1992, M692.

[20]. R. Tiwari, H. Herman, S. Sampath, B. Gudmundsson, "Plasma spray consolidation of high temperature composites", Materials Science and Engineering: A, Volume 144, Issues 1-2, 1 October 1991, pages 127-13.

[21]. Sug Won Kim, Ui Jong Lee, Sang Won Han, Dong Keun Kim, K. Ogi, "Heat treatment and wear characteristics of $\mathrm{Al} / \mathrm{SiCp}$ composites fabricated by duplex process", Composites: Part B 34 (2003) 737-745.

[22]. B.K. Prasad, "Investigation into sliding wear performance of zinc-based alloy reinforced with SiC particles in dry and lubricated conditions", Wear 262 (2007) 262-273.

[23]. M.R. Rosenberger, C.E. Schvezov, E. Forlerer, "Wear of different aluminum matrix composites under conditions that generate a mechanically mixed layer", Wear 259 (2005) $590-601$.

[24]. L.J. Yang "A test methodology for the determination of wear coefficient", Wear 259 (2005) 1453-1461.

[25]. L.J. Yang, "Wear coefficient equation for aluminium-based matrix composites against steel disc", Wear 255 (2003) 579-592.

[26]. A.R. Riahi, A.T. Alpas, "The role of tribo-layers on the sliding wear behavior of graphitic aluminum matrix composites", Wear 251 (2001) 1396-1407.

[27]. Szu Ying Yu, Hitoshi Ishii, Keiichiro Tohgo, Young Tae Cho, Dongfeng Diao, "Temperature dependence of sliding wear behavior in $\mathrm{SiC}$ whisker or $\mathrm{SiC}$ particulate reinforced 6061 aluminum alloy composite", Wear 213 (1997) 21-28.

[28]. S. Wilson, A.T. Alpas "Wear mechanism maps for metal matrix composites", Wear 212 (1997) 41-49.

[29]. H.C. How, T.N. Baker, "Dry sliding wear behaviour of saffil-reinforced AA6061 composites", Wear 210 (1997) 263-272.

[30]. S.Wilson, A.T.Alpas, "Effect of temperature on the sliding wear performance of Al alloys and Al matrix composites", Wear 196 (1996) 270-278.

[31]. A.B.Gurcan, T.N.Baker, "Wear behavior of AA6061 aluminum alloy and its composites", Wear 188 (1995) 185-191.

[32]. C.garcia-Cordovilla, J.Narciso, E.Louis "Abrasive wear resistance of aluminum alloy/ceramic particulate composites", Wear 192 (1996) 170-177.

[33]. S.C. Sharma, "The sliding wear behavior of Al6061-garnet particulate composites", Wear 249 (2001) 1036-1045.

[34]. I.M. Hutching, "Wear by particulates", Chemical Engineering Science, Volume 42, Issue 4, 1987, Pages 869-878. 
[35]. F. M. Husking, F. Folgar Portillo, R. Wunderlin, R. Mehrabian, "Comlpsites of aluminium alloys: fabrication and wear behaviour", J. Mater. Sci. 17 (1982) 477-498.

[36]. Debdas Roy, Bikramjit Basu, Amitava Basu Mallick, "Tribological properties of Tialuminide reinforced Al-based in situ metal matrix composite", Intermetallics 13 (2005) 733-740.

[37]. Uan JY, Chen LH, Lui TS, "On the extrusion microstructural evolution of Al-Al3Ni in situ composite", Acta Materialia, Volume 49, Issue 2, 2001, Pages 313-320.

[38]. Rajnesh Tyagi, "Synthesis and tribological characterization of in situ cast Al-TiC composites", Wear 259 (2005) 569-576.

[39]. P.H. Shipway, A.R. Kennedy, A.J. Wilkes, "Sliding wear behaviour of aluminium-based metal matrix composites produced by a novel liquid route", Wear 216 (1998) 160 -171.

[40]. S.K. Chaudhury, A.K. Singh, C.S. Sivaramakrishnan, S.C. Panigrahi, "Wear and friction behavior of spray formed and stir cast Al-2Mg-11TiO 2 composites", Wear 258 (2005) 759-767.

[41]. Abdulhaqq A. Hamid, P.K. Ghosh, S.C. Jain, Subrata Ray, "The influence of porosity and particles content on dry sliding wear of cast in situ $\mathrm{Al}(\mathrm{Ti})-\mathrm{Al}_{2} \mathrm{O}_{3}\left(\mathrm{TiO}_{2}\right)$ composite", Wear, Volume 265, Issues 1-2, 25 June 2008, Pages 14-26.

[42]. Abdulhaqq A. Hamid, P.K. Ghosh, S.C. Jain, S. Ray, "Influence of particle content and porosity on the wear behaviour of cast in situ $\mathrm{Al}(\mathrm{Mn})-\mathrm{Al}_{2} \mathrm{O}_{3}\left(\mathrm{MnO}_{2}\right)$ composite", Wear 260 (2006) 368-378.

[43]. I.M. Hutchings, Mater. Sci. Technol. 10 (1994) 513-517.

[44]. D.J. Lloyd, Int. Met. Rev. 39 (1984) 1-23.

[45]. G.J.Howell, A.Ball, "Dry sliding wear of particulate-reinforced aluminium alloys against automobile friction materials", Wear 181-183 (1995) 379-390.

[46]. A. Vencl, I. Bobi, Z. Mijskovi, "Effect of thixocasting and heat treatment on the tribological properties of hypoeutectic Al-Si alloy”, Wear 264 (2008) 616-623.

[47]. J.M. Wu, Z.Z. Li, "Contributions of the particulate reinforcement to dry sliding wear resistance of rapidly solidified Al-Ti alloys", Wear 244 (2000) 147-153.

[48]. R.L. Deuis, C. Subramaniun, J.M. Yellup, “Abrasive wear of aluminium composites-a review", Wear 201 (1996) 132-144.

[49]. B.K. Prasad, O.P. Modi, A.K. Jha, "The effects of alumina fibres on the sliding wear of a cast aluminium alloy”, Tribo., Inter., Volume 27, Issue 3, June 1994, Pages 153-158.

[50]. Alpas AT, Zhang J., "Effect of SiC particulate reinforcement on the dry sliding wear of aluminum-silicon alloys (A356)", Wear 1992; 155:83-104.

[51]. Kulkarni MD, Robi PS, Prasad RC, Ramakrishnan P., "Deformation and fracture behavior of cast and extruded 7075Al-SiCp composites at room and elevated temperatures", Mater Trans, JIM 1996; 37:223-9.

[52]. Kim CK, Park SY, "A study on the fabrication and mechanical properties of SiC fiberaluminum alloy composites”, J Korean Inst Met Mater 1984; 22:185-92. 
[53]. C. Subramanian, "Some considerations towards the design of a wear resistant aluminium alloy", Wear 155 (1992) 193-205.

[54]. M. Chen, T. Perry, A.T. Alpas, "Ultra-mild wear in eutectic Al-Si alloys", Wear 263 (2007) 552-561.

[55]. S. Sawla, S. Das, "Combined effect of reinforcement and heat treatment on the two body abrasive wear of al-alloy and aluminum particle composites", Wear 257 (2004) 555-561.

[56]. W.Q.Song, P.Krauklis, A.P.Mouritz, S.Bandyopadhyay, "The effect of thermal ageing on the abrasive wear behavior of age-hardening $2014 \mathrm{Al} / \mathrm{SiC}$ and $6061 \mathrm{Al} / \mathrm{SiC}$ composites", Wear 185 (1995) 125-130.

[57]. S. Das, D.P. Mondal, S. Sawla, N. Ramakrishnan, "Synergic effect of reinforcement and heat treatment on the two body abrasive wear of an Al-Si alloy under varying loads and abrasive sizes", Wear 264 (2008) 47-59.

[58]. Wang .A and H.J. Rack, "Abrasive wear of silicon carbide particulate and whisker reinforced 7091 aluminium matrix composites", Wear, 146 (1991) 337.

[59]. Callister Jr. W. D., "Materials Science and Engineering: an introduction", New York, Wiley, year 1999.

[60]. James M. Whitney and Roy L. Mc Cullough, "Micromechanical materials modeling", in vol. 2 of Delware composite design Encyclopedia, Trchnomic Publishing Company.

[61]. L.E. Nielson and R.F. Landel, "Mechanical properties of polymers and composites", Marcel Dekker, Inc. New York, year 1994.

[62]. Shao-Yun $\mathrm{Fu}$, Guanshui $\mathrm{Xu}$ and Yiu-Wing Mai, "On the elastic modulus of hybrid particle/short-fiber/polymer composites”, Composites: Part B33: 291-299, 2002.

[63]. Soon-Chul Kwon, Tadahrru Adachi, Wakako Araki and Akihiko Yamaji, "Thermoviscoelastic properties of silica particulate-reinforced epoxy composites: Considered in terms of particle packing model”, Acta Materialia 54 (2006) 3369-3374.

[64]. Manwar Hussain, Atsushi Nakahira, Shigehiro Nishijima and Koichi Niihara, "Effects of coupling agents on the mechanical properties improvement of the $\mathrm{TiO}_{2}$ reinforced epoxy system", Materials Letters 26:299-303, 1996.

[65]. Ma ZY, Tjong SC. In situ ceramic particle-reinforced aluminum matrix composites fabricated by reaction pressing in the $\mathrm{TiO}_{2}(\mathrm{Ti})-\mathrm{Al}-\mathrm{B}\left(\mathrm{B}_{2} \mathrm{O}_{3}\right)$ systems. Metall. Mater. Trans. 1997; 28(A):1931-42.

[66]. Rang Chen, Akira lwabuchi, Tomoharu Shimizu, Hyung Seop Shin, Hidenobu Mifune, "The sliding wear resistance behavior of NiAI and $\mathrm{SiC}$ particles reinforced aluminum alloy matrix composites", Wear 213 (1997) 175-184.

[67]. Yoshiro Iwai, Hidetomo Yoneda, Tomomi Honda, "Sliding wear behavior of SiC whisker-reinforced aluminum composite", Wear 181-183 (1995) 594-602.

[68]. Heguo Zhu., Hengzhi Wang, Liangqi Ge, "Wear properties of the composites fabricated by exothermic dispersion reaction synthesis in an $\mathrm{Al}-\mathrm{TiO}_{2}-\mathrm{B}_{2} \mathrm{O}_{3}$ system", Wear, Volume 264, Issues 11-12, 10 May 2008, Pages 967-972. 
[69]. A.Martin, M.A.Martinez, J.LLorca, "Wear of SiC-reinforced Al-matrix composites in the temperature range 20-200 C", Wear 193 (1996) 169-179.

[70]. H. Sekine, R. Chen, "A combined microstructure strengthening analysis of SiCprAl metal matrix composites", Composite 6 (1995) 183-188.

[71]. R. Chen, G.D. Zhang, "Casting defects and properties of cast A356 alloy reinforced with SiC particulates", Compos. Sci. Technol. 4 (1993) 511-556.

[72]. P.M. Singh, J.J. Lewandowski, "Effects of heat treatment and reinforcement size on reinforcement fracture during tension testing of a SiCp discontinuously reinforced aluminum alloy", Metall. Trans. A 24 (1993) 2531-2543.

[73]. Rong Chen, Akira Iwabuchi, Tomoharu Shimizu, "The effect of a T6 heat treatment on the fretting wear of a SiC particle-reinforced A356 aluminum alloy matrix composite", Wear 238 (2000) 110-119.

[74]. J. LLorca, "Failure micro-mechanisms in particulate-reinforced metal matrix composites", J. Phys. IV, 3 (1993) 1793-1798.

[75]. J.R. Gomes, A. Ramalho, M.C. Gaspar, S.F. Carvalho, "Reciprocating wear tests of AlSi/SiCp composites: A study of the effect of stroke length", Wear 259 (2005) 545-552.

[76]. H.C. How, T.N. Baker, "Characterization of sliding friction-induced subsurface deformation of Saffil-reinforced AA6061 composites", Wear 232 (1999) 106-115.

[77]. Peter J, Blau, "Fifty years of research on the wear of metals", Tribology International Vol. 30, No. 5, pp. 321-331, 1997.

[78]. U. Sanchez-Santana, C. Rubio-Gonzalez, G. Gomez-Rosas, J.L. Ocana, C. Molpeceres, J. Porro, M. Morales, "Wear and friction of 6061-T6 aluminum alloy treated by laser shock processing”, Wear 260 (2006) 847-854.

[79]. A.P.Sannino, H.J.Rack, "Dry sliding wear of discontinuously reinforced aluminium composites: review and discussion”, Wear 189 (1995) 1-19.

[80]. R.K. Uyyuru., M.K. Surappa, S. Brusethaug, "Effect of reinforcement volume fraction and size distribution on the tribological behavior of Al-composite/brake pad tribocouple", Wear 260 (2006) 1248-1255.

[81]. A.T. Alpas, J. Zhang, "Effect of microstructure (particulate size and volume fraction) and counterface material on the sliding wear resistance of particulate-reinforced aluminum matrix composites", Metall. Mater. Trans. A 25 (1994) 969-983.

[82]. M.K. Surappa, S.V. Prasad, P.K. Rohatgi, "Wear and abrasion of cast Al-alumina particle composites", Wear 77 (1982) 295-302.

[83]. A. Wang, H.J. Rack, "Dry sliding wear in 2124 Al-SiCw/17-4 PH stainless steel systems", Wear 147 (1991) 355-374.

[84]. J.P. Tu, Y.Z. Yang, "Tribological behaviour of Al18B4O33-whisker reinforced hypoeutectic Al-Si-Mg-matrix composites under dry sliding conditions", Composite Science Technology, 60 (2000) 1801-1809. 
[85]. M. Bai, Q. Xue, X. Wang, Y. Wan, W. Liu, "Wear mechanism of SiC whisker-reinforced 2024 al-alloy matrix composites in oscillating sliding wear tests", Wear 185 (1995) 197202.

[86]. A. Alahelisten, F. Bergman, M. Olsson, S. Hogmark, "On the wear of aluminium and magnesium metal matrix composites", Wear 165 (1993) 221-226.

[87]. J.Q. Jiang, R.-S. Tan, A.-B. Ma, "Dry sliding wear behaviour of $\mathrm{Al}_{2} \mathrm{O}_{3}-\mathrm{Al}$ composites produced by centrifugal force infiltration", Mater. Sci. Technol. 12 (1996) 483-488.

[88]. P.N. Bindumadhavan, H.K. Wah, O. Prabhakar, "Dual particle size (DPS) composites: effect on wear and mechanical properties of particulate matrix composites", Wear 248 (2001) 112-120.

[89]. D.P. Mondal, S. Das, A.K. Jha, A.H. Yegneswaran, "Abrasive wear of $\mathrm{Al}$ alloy- $\mathrm{Al}_{2} \mathrm{O}_{3}$ particle composite: a study on the combined effect of load and size of abrasive", Wear 223 (1998) 131-138.

[90]. S. Kumar, V. Balasubramanian, "Developing a mathematical model to evaluate wear rate of AA7075/SiCp powder metallurgy composites", Wear, Volume 264, Issues 11-12, 10 May 2008, Pages 1026-1034.

[91]. A. Martin, J. Rodriguez, J. Llorca, "Temperature effects on the wear behavior of particulate reinforced Al-based composites", Wear 225-229 (1999) 615-620.

[92]. Joel Hemanth, "Tribological behavior of cryogenically treated $\mathrm{B}_{4} \mathrm{C}_{\mathrm{p}} / \mathrm{Al}-12 \% \mathrm{Si}$ composites", Wear 258 (2005) 1732-1744.

[93]. R.K. Uyyuru, M.K. Surappa, S. Brusethaug, "Tribological behavior of Al-Si-SiC composites/automobile brake pad system under dry sliding conditions", Tribology International 40 (2007) 365-373.

[94]. Gibson R, Clegg AJ, Das AA, "Wear of cast Al-Si alloys containing graphite", Wear, Volume 95, Issue 2, 16 April 1984, Pages 193-198.

[95]. J. Zhang, A.T. Alpas, "Delamination wear in ductile materials containing second phase particles", Materials Science and Engineering: A, Volume 160, Issue 1, 15 January 1993, Pages 25-35.

[96]. Y. Wang, W.M. Rainforth, H. Jones, M. Lieblich, "Dry wear behaviour and its relation to microstructure of novel 6092 aluminium alloy-Ni3Al powder metallurgy composite", Wear 251 (2001) 1421-1432.

[97]. Ferhat Gul, Mehmet Acilar, "Effect of the reinforcement volume fraction on the dry sliding wear behaviour of $\mathrm{Al}-10 \mathrm{Si} / \mathrm{SiCp}$ composites produced by vacuum infiltration technique", Composites Science and Technology 64 (2004) 1959-1970.

[98]. C. Perrin, W.M. Rainforth, "The effect of alumina fibre reinforcement on the wear of an Al-4.3\% Cu alloy", Wear 181-183 (1995) 312.

[99]. G. Ranganath, S.C. Sharma, M. Krishna, "Dry sliding wear of garnet reinforced zinc/aluminium metal matrix composites", Wear 251 (2001) 1408-1413. 
[100]. Q.D. Qin, Y.G. Zhao, W. Zhou, "Dry sliding wear behavior of $\mathrm{Mg}_{2} \mathrm{Si} / \mathrm{Al}$ composites against automobile friction material", Wear, Volume 264, Issues 7-8, 15 March 2008, Pages 654-661.

[101]. K.M. Shorowordi, A.S.M.A. Haseeb, "Velocity effects on the wear, friction and tribochemistry of aluminum MMC sliding against phenolic brake pad", Wear 256 (2004) 1176-1181.

[102]. J.K.M. Kwok, S.C. Lim, "High-speed tribological properties of some Al/SiCp composites. I. Frictional and wear-rate characteristics", Composite Science and Technology 59 (1999) 55-63.

[103]. P. Poza, M.A. Garrido, A. Rico, J. Rodriguez, "Dry sliding wear behaviour of aluminium-lithium alloys reinforced with SiC particles", Wear 262 (2007) 292-300.

[104]. P. Vissutipitukul, T. Aizawa, "Short communication; Wear of plasma-nitrided aluminum alloys", Wear 259 (2005) 482-489.

[105]. J. Zhang, A.T. Alpas, "Transition between mild and severe wear in aluminum alloys", Acta Materia 45 (2) (1997) 513-528.

[106]. L.J. Yang, "The effect of nominal specimen contact area on the wear coefficient of A6061 aluminium matrix composite reinforced with alumina particles", Wear 263 (2007) 939-948.

[107]. E. Hornbogen, "The role of fracture toughness in the wear of metals", Wear 33 (1975) 251-259.

[108]. S. Das, "The influence of matrix microstructure and particle reinforcement on the twobody abrasive wear of cast Al-Si-alloy composites”, J. Mater. Sci. Lett. 16 (1997) 17571760.

[109]. S. Das, S. Gupta, D.P. Mondal, B.K. Prasad, "Influence of load and abrasive size on the two body abrasive wear of Al-SiC composites", Aluminum Trans. 2 (2000) 27-36.

[110]. S. Das, D.P. Mondal, G. Dixit, "Mechanical properties of pressure die cast Al hard part composite", Metall. Mater. Trans. 33A (2001) 633-642.

[111]. G.Y. Lee, C.K.H. Dharan, R.O. Ritchie, "A physically based abrasive wear model for composite materials", Wear 252 (3-4) (2002) 322-331.

[112]. A.A. Torrance, "The effect of grit size and asperity blunting on abrasive wear", Wear 253 (2002) 813-819.

[113]. H.L. Lee, W.H. Lu, S. Chan, "Abrasive wear of powder metallurgy Al alloy 6061-SiC particle composites", Wear 159 (1992) 223-231.

[114]. L. Ceschini, G.S. Daehn h, G.L. Garagnani, C. Martini, "Friction and wear behavior of C 4 AI203/AI composites under dry sliding conditions", Wear 216 (1998) 229-238.

[115]. Feng Tang, Xiaoling Wu, Shirong Gec, Jichun Ye, Hua Zhu, Masuo Hagiwara, Julie M. Schoenung, "Dry sliding friction and wear properties of B4C particulate-reinforced Al5083 matrix composites", Wear, Volume 264, Issues 7-8, 15 March 2008, Pages 555-561. 
[116]. O.P. Modi, B.K. Prasad, A.H. Yegneswaran, M.L. Vaidya, "Dry sliding wear behaviour of squeeze cast al-alloy-silicon carbide composites", Mater. Sci. Eng. A 151 (1992) 235245.

[117]. J. Zhang, A.T. Alpas, "Wear regimes and transitions in Al2O3 particulate-reinforced aluminium alloys", Mater. Sci. Eng. A 161 (1993) 273-284.

[118]. B.J. Li, C.G. Chao, "Mechanical properties and $95^{\circ}$ aging characteristics of zirconreinforced Zn-4AI-3Cu alloy", Metall. Mater. Trans. A 27A (1996) 809-818.

[119]. Y. Sahin, "Wear behaviour of planar-random fibre-reinforced metal matrix composites", Wear 223 (1998) 173-183.

[120]. H.X. Zhu, S.K. Liu, "Mechanical properties of squeeze-cast zinc alloy matrix composites containing $\alpha$-alumina fibres", Composites 5 (1993) 437-442.

[121]. S. Muthukumarasamy, S. Seshan, "Structure and properties of fibre reinforced zn-27\% al alloy based cast MMCs", Composites 26 (1995) 387-393.

[122]. A.K. Prasada Rao, K. Das, B.S. Murty, M. Chakraborty, "Microstructure and the wear mechanism of grain-refined aluminum during dry sliding against steel disc", Wear, Volume 264, Issues 7-8, 15 March 2008, Pages 638-647.

[123]. A.P.sannino, H.J.Rack, "Tribological investigation of 2009 Al-20 vol. \% $\mathrm{SiC}_{\mathrm{P}} /$ 17-4 PH Part I: Composite performance”, Wear 197 (1996) 151-159.

[124]. K.H. Zum Gahr, Met. Prog, 116 (1979), 46.

[125]. V. Jayaram, S.K. Biswas, "Wear of Al $2 \mathrm{O}-\mathrm{SiC}$ [Al, Si] melt oxidized ceramic composites", Wear 225-229 (1999) 1322-1326.

[126]. M.Y. Chen, M.C. Breslin, "Friction behavior of co-continuous alumina/aluminum composites with and without SiC reinforcement", Wear 249 (2002) 868-876.

[127]. M.H. Korkut, "Microstructure and wear behavior of Al2024lSiFe and Al2024 $\backslash \mathrm{SiFe} \backslash \mathrm{Al}_{2} \mathrm{O}_{3}$ composites", Tribology International 36 (2003) 169-180.

[128]. J.C. Walker, W.M. Rainforth, H. Jones, "Lubricated sliding wear behaviour of aluminium alloy composites", Wear 259 (2005) 577-589.

[129]. A. Mandal, M. Chakraborty, B.S. Murty, "Effect of TiB2 particles on sliding wear behaviour of Al-4Cu alloy", Wear 262 (2007) 160-166.

[130]. S.V. Nair, J.K. Tien, R.C. Bates, "SiC-reinforced aluminium metal matrix composites", Int. Mater. Rev. 30 (6) (1985) 275-290.

[131]. I.A. Ibrahim, F.A. Mohamed, E.J. Lavernia, "Particulate reinforced metal matrix composites - a review", J. Mater. Sci. 26 (1991) 1137-1156.

[132]. C.S. Ramesh, R. Keshavamurthy, B.H. Channabasappa, Abrar Ahmed, "Microstructure and mechanical properties of Ni-P coated Si3N4 reinforced Al6061 composites", Materials Science and Engineering: A, Volume 502, Issues 1-2, 25 February 2009, Pages 99-106.

[133]. D.J. Lloyd, H. Lagace, A. McLeod, P. L. Morris, "Microstructural aspects of aluminiumsilicon carbide particulate composites produced by a casting method", Materials Science and Engineering: A, Volume 107, January 1989, Pages 73-80. 
[134]. T.F. Stephenson, J.A.E. Bell, in: R.A.L. Drew, H. Mostaghaci (Eds.), "Development and Applications of Ceramics and New Metal Alloys”, CIM, Montreal, 1993, p. 51.

[135]. Z. Ma, L. Ya'nan, Y. Lu, J. Bi, Trans. Nonferrous Met. Soc. 8 (1998) 556-561.

[136]. P.R. Gibson, A.J. Clegg, A.A. Das, Mater. Sci. Technol. 1 (1985) 559.

[137]. S. Das, S.V. Prasad, T.R. Ramachandran, "Tribology of Al---Si alloy-graphite composites: triboinduced graphite films and the role of silicon morphology", Materials Science and Engineering: A, 138 (1991) 123.

[138]. S. Das, S.V. Prasad, "Microstructure and wear of cast (Al-Si alloy)-graphite composites", Wear, 133 (1989) 173.

[139]. P.K. Rohatgi, Y. Liu, T.L. Barr, Metall. Trans. A 22 (1991) 1435.

[140]. W. Ames, A.T. Alpas, Metall. Mater. Trans. A 26 (1995) 85.

[141]. S.V. Prasad and P. K. Rohatgi, "Tribological properties of Al alloy particle composites", J. Met., 39(11) (1987) 22-26.

[142]. P.K. Rohatgi, S. Ray, Y. Liu, "Tribological properties of metal matrix graphite particle composites", Int. Mater. Rev. 37 (1992), pp. 129-149.

[143]. O.P. Modi, R.P. Yadav, B.K. Prasad, A.K. Jha, S. Das, A.H. Yegneswaran, "Three-body abrasion of a cast zinc-aluminium alloy: influence of $\mathrm{A} 12 \mathrm{O} 3$ dispersoid and abrasive medium", Wear 249 (2001) 792-799.

[144]. M.J. Ghazali, W.M. Rainforth , H. Jones, "Dry sliding wear behaviour of some wrought, rapidly solidified powder metallurgy aluminium alloys”, Wear 259 (2005) 490-500.

[145]. R. Antoniou, D.W. Borland, Mater. Sci. Eng. A 93 (1987) 57-72.

[146]. A.Ravikiran, M.K.Surappa, "Effect of Sliding speed on wear behavior of A356 Al-30\% SiCP MMC”, Wear 206 (1997) 33-38.

[147]. X.Y. Li, K.N. Tandon, "Microstructural characterization of mechanically mixed layer and wear debris in sliding wear of an Al alloy and an Al based composite", Wear 245 (2000) 148-161.

[148]. B. Venkataraman, G. Sundararajan, "Correlation between the characteristics of mechanically mixed layer and wear behaviour of aluminium, Al-7075 alloy and AlMMCs", Wear 245 (2000) 22-38.

[149]. N. Saka, J.J. Pamies-Teixeira, N.P. Suh, "Wear of two-phase metals", Wear 44 (1977) 77-86.

[150]. R. Tyagi, S.K. Nath, S. Ray, "Effect of martensite content on friction and oxidative wear behavior of 0.42 Pct carbon dual-phase steel", Metallurgical and Materials Transactions A 33A (2002) 3479-3488.

[151]. X.Y. Li, K.N. Tandon, "Mechanical mixing induced by sliding wear of an Al-Si alloy against M2 steel", Wear 225-229 (1999) 640-648.

[152]. S.K. Biswas, "Some mechanisms of tribofilm formation in metal/metal and ceramic/metal sliding interactions”, Wear 245 (2000) 178-189. 
[153]. L. Las, J.M. Rodrigez-Ibabe, "Wear behaviour of eutectic and hypereutectic $\mathrm{Al}-\mathrm{Si}-\mathrm{Cu}-$ Mg casting alloys tested against a composite brake pad", Mater. Sci. Eng. A 363 (2003) 193-200.

[154]. J.M. Gomez de Salazar, M. I. Barrena, "Influence of heat treatments on the wear behaviour of an AA6092/SiC25p composite", Wear 256 (2004) 286-293.

[155]. M. Singh, O.P. Modi, Rupa Dasgupta, A.K. Jha, "High stress abrasive wear behaviour of aluminium alloy-granite particle composite", Wear 233-235 (1999) 455-461.

[156]. Veeresh Kumar.G.B, C.S.P.Rao, Bhagyashekar.M.S, Selvaraj.N "Mechanical and Tribological Behaviour of Al6061-SiCp Composites", proceedings of the International Conference ICMM-2008, 18th-20th December 2008, pp 1-8.

[157]. Hulya Kaçar Durmuş, Erdogan Ozkaya and Cevdet Meric, "The use of neural networks for the prediction of wear loss and surface roughness of AA $6351 \mathrm{Al}$ alloy", Materials \& Design, Vol 27, Issue 2, Pgs 156-159, 2006.

[158]. Y. Sahin, "The prediction of wear resistance model for the metal matrix composites", Wear 258 (2005) 1717-1722.

[159]. C.S. Ramesh, A.R. Anwar Khan, N. Ravikumar, P. Savanprabhu, "Prediction of wear coefficient of Al6061-TiO2 composites", Wear 259 (2005) 602-608.

[160]. Lin Ye, Ye Lu, Zhongqing Su, Guang Meng, "Functionalized composite structures for new generation airframes: a review", Composites Science and Technology 65 (2005) $1436-1446$.

[161]. Z. Zhang, K. Friedrich, "Artificial neural networks applied to polymer composites: a review", Composites Science and Technology 63 (2003) 2029-2044.

[162]. Rasit Koker, Necat Altinkok and Adem Demir, "Neural network based prediction of mechanical properties of particulate reinforced metal matrix composites using various training algorithms", Materials \& Design, Vol 28, pp 616-627, 2007.

[163]. Zhenyu Jiang, Zhong Zhang and Klaus Friedrich, "Prediction on wear properties of polymer composites with artificial neural networks", Composites Science and Technology, Volume 67, Issue 2, Pages 168-176, February 2007.

[164]. Holger R. Maier, Graeme C. Dandy, "The effect of internal parameters and geometry on the performance of back-propagation neural networks: an empirical study, Environmental Modelling \& Software, Volume 13, Pages 193 - 209, (1998).

[165]. H. S. Rao and A. Mukherjee, "Artificial neural networks for predicting the macromechanical behaviour of ceramic-matrix composites", Computational Materials Science, Volume 5, Issue 4, Pages 307-322, April 1996.

[166]. P. Cavaliere, "Flow curve prediction of an Al-MMC under hot working conditions using neural networks", Computational Materials Science, Vol 38, Issue 4, Pg 722-726, Feb 2007.

[167]. Adel Mahamood Hassan, Abdalla Alrashdan, Mohammed T. Hayajneh, Ahmad Turki Mayyas, "Prediction of density, porosity and hardness in aluminum-copper-based 
composite materials using ANN", Journal of Materials Processing Technology, 209, pp 894-899, 2009.

[168]. Necat Altinkok and Rasit Koker, "Modeling of the prediction of tensile and density properties in particle reinforced metal matrix composites by using neural networks", Materials \& Design, Volume 27, Issue 8, Pages 625-631, 2006.

[169]. C. Z. Huang, L. Zhang, L. He, J. Sun, B. Fang, B. Zou, Z. Q. Li and X. Ai, “A study on the prediction of the mechanical properties of a ceramic tool based on an artificial neural network, Journal of Materials Processing Technology, Volume 129 (2002), pp 399-402.

[170]. G. Partheepan, D.K. Sehgal,R.K. Pandey, "Fracture toughness evaluation using miniature specimen test and neural network", Computational Materials Science, 44, pp 523-530, 2008.

[171]. Abeesh C. Basheer, Uday A. Dabade, Suhas S. Joshi, V.V. Bhanuprasad and V.M. Gadre "Modeling of surface roughness in precision machining of metal matrix composites using ANN", Journal of Materials Processing Technology, Volume 197, Issues 1-3, pp 439444, Feb 2008.

[172]. G. Ganesan, K. Raghukandan, R. Karthikeyan and B.C. Pai, "Development of processing map for $6061 \mathrm{Al} / 15 \% \mathrm{SiCp}$ through neural networks", Journal of Materials Processing Technology, Volume 166, Issue 3, pp 423-429, August 2005.

[173]. Sumantra Mandal, P.V. Sivaprasad, S. Venugopal, K.P.N. Murthy, "Artificial neural network modeling to evaluate and predict the deformation behavior of stainless steel type AISI 304L during hot torsion", Applied Soft Computing, 9, pp 237-244, 2009.

[174]. Mehmet Sirac Ozerdem, Sedat Kolukisa, "ANN approach to predict the mechanical properties of $\mathrm{Cu}-\mathrm{Sn}-\mathrm{Pb}-\mathrm{Zn}-\mathrm{Ni}$ cast alloys", Materials and Design, 30, 764$769,2009$.

[175]. Jiahua Zhu, Yijun Shi, Xin Feng, Huaiyuan Wang, Xiaohua Lu, "Prediction on tribological properties of carbon fiber and $\mathrm{TiO}_{2}$ synergistic reinforced polytetrafluoroethylene composites with artificial neural networks", Materials and Design, 30, pp 1042-1049, 2009.

[176]. K.Genel, S.C Kurnaz, M. Durman "Modeling of tribological properties of alumina fiber reinforced zinc-Al composites using Artificial Neural Network", Material Science and engineering A, Volume 363, pages 203-210, December 2003.

[177]. Raimundo Carlos Silverio Freire Jr., Adriao Duarte Doria Neto, Eve Maria Freire de Aquino, "Use of modular networks in the building of constant life diagrams", International Journal of Fatigue 29 (2007) 389-396.

[178]. F.S.Rashed, T.S.Mahmoud, "Prediction of wear behaviour of A356/SiCp MMCs using neural networks", Tribology International 42 (2009) 642-648.

[179]. Veeresh Kumar.G.B, C.S.P.Rao, Selvaraj.N, Bhagyashekar.M.S., "Prediction of Wear of Al6061-SiC Metal Matrix Composites using Artificial Neural Networks", International Journal of Computer Applications in Engineering, Technology and Sciences (IJ-CA-ETS) Volume 2, Issue 1, pp. 498-505, October 2009 - March 2010. 
[180]. Arjula Suresh, A.P. Harsha, M.K. Ghosh, "Solid particle erosion studies on polyphenylene sulfide composites and prediction on erosion data using artificial neural networks", Wear 266, pp 184-193, 2009.

[181]. Abderrezak Bezazi, S. Gareth Pierce, Keith Worden, El Hadi Harkati, "Fatigue life prediction of sandwich composite materials under flexural tests using a Bayesian trained artificial neural network", International Journal of Fatigue, Vol 29, pp 738-747, 2007.

[182]. M.R. Dashtbayazi, A. Shokuhfar and A. Simchi, "ANN modeling of mechanical alloying process for synthesizing of metal matrix nanocomposite powders", Materials Science and Engineering: A, Vol 466, Pg 274-283, 25 Sept 2007. 